\title{
Barriendo las calles: Sociedad civil y seguridad ciudadana en Rótterdam
}

\author{
René van Swaaningen \\ Universidad Erasmus de Rótterdam \\ vanSwaaningen@frg.eur.nl
}

\section{Introducción}

En el periódico holandés NCR Handelsblad del 25 de octubre de 2004 pueden verse en portada dos titulares aparentemente contradictorios: "A la gente le da miedo una sociedad endurecida" y "Cohen (el alcalde de Ámsterdam, del $R v S$ ) quiere ordenar la prohibición de la conducta incívica". El primero de los artículos es acerca del Informe bianual Cultura y Sociedad del año 2004 en el que se entrevista a unas dos mil personas sobre sus deseos y expectativas para la Holanda del 2020. Según dicho informe, existe disparidad entre lo que la gente desea y las que, de hecho, son sus expectativas para el futuro. Desearían una sociedad con mayor cohesión social y más solidaria, pero se temen que ésta será cada vez más competitiva y que el clima social continuará endureciéndose $^{1}$. El segundo artículo es sobre un grupo de chicos marroquíes que "aterroriza" a un concreto vecindario de clase media en Ámsterdam, y el resultado de cuya actividad ha sido que una familia se ha visto forzada a mudarse y que algunos hombres homosexuales se sientan amenazados por esos chicos. Si los estimados en 20 delincuentes habituales que se encuentran en ese grupo, contra los que pesa una orden de no volver a entrar en el vecindario, son vistos una sola vez más ya pueden contar con una sentencia de prisión de más de dos años en un régimen especial "sin contemplaciones"2

\footnotetext{
${ }^{1}$ El Informe Cultura y Sociedad 2004 se encuentra en línea en: http://www.scp.nl/publicaties/boeken/9037701590.shtml. Por su parte el informe Calidad y Futuro: una concepción de la sostenibilidad (Kwaliteit en Toekomst. Verkenning van duurzaamheid) del Instituto Nacional para la Salud Pública y el Medioambiente (RIVM), que apareció una semana antes que el informe del SCP mencionado, muestra una orientación similar. Se encuentra en línea en: http://www.rivm.nl/bibliotheek/rapporten/500013009.pdf

${ }^{2}$ Esto ha sido posible gracias a la nueva Ley sobre Instituciones para Delincuentes Habituales (ISD) que está en vigor desde el primero de octubre de 2004 -los nuevos artículos 38m-38u de la Ley de Enjuiciamiento Criminal holandesa (WvSv). Se la conoce como la versión descafeinada de la legislación estadounidense de las "tres infracciones y quedas fuera de juego" (three strikes and you're out).
}

Revista Española de Investigación Criminológica

Artículo 2, Número 5 (2007) $\quad$ www.criminología.net

ISSN: $1696-9219$ 
¿Cuál es el papel de la sociedad civil en el desarrollo de las políticas sobre delincuencia local y seguridad? Esta es la cuestión que deseo tratar en este ensayo. Los dos artículos citados muestran una imagen más bien contradictoria. Por un lado, la gente está a favor de endurecer las sanciones, y por el otro sostiene que no le gusta que la sociedad esté yendo por ese camino. El deseo de la gente de mayor cohesión social y más solidaridad claramente no se refleja en las reacciones frente al delito y la conducta incívica.

A lo largo de los últimos 10 años solo un pequeño porcentaje de la población ha manifestado sentirse frecuentemente inseguro en un sentido general; un número relativamente grande de personas teme que los problemas con los que nos enfrentaremos en el 2020 serán mayores que los que tenemos ahora: se menciona con frecuencia el terrorismo (islamista) y la violencia en las calles. Hoy en día la gente dice tener más miedo de los grupos de jóvenes (entre los que más temen a marroquíes y antillanos) que están mendigando agresivamente, vandalizando sus vecindarios e intimidando a los residentes.

La mayoría de las personas entrevistadas por La Oficina de Planificación Social y Cultural (SCP), creen que la creciente competitividad de la sociedad, la disminución del control social informal, y la globalización son las principales causas del delito y de la conducta incívica, pero las soluciones que esperan ver llegar no guardan relación con ese planteamiento. Puesto que, en concreto, conseguir que disminuya la competitividad o que se revierta el proceso de globalización parece algo imposible, se vislumbran nuevas intervenciones en la privacidad (principalmente mediante el aumento de la vigilancia por cámaras y el establecimiento de bases de datos generales de ADN para la identificación de culpables), o que más empresas de seguridad privada den asistencia a la policía. Y aunque, en particular las autoridades locales han realizado esfuerzos para incrementar el control social informal, existe casi un $100 \%$ de apoyo popular a favor del endurecimiento de las penas -especialmente para los delitos violentos- y en el mejor de los casos una actitud con reservas frente al control social informal. Resulta llamativo el que muchos ciudadanos también deseen que las autoridades presten mayor atención a la prevención social del delito y la conducta incívica, pero al mismo tiempo no sean muy optimistas respecto de su efectividad. Muchos de ellos (83\%) prevén que la seguridad en sus barrios se ira convirtiendo en su propia responsabilidad, aunque un $40 \%$ 
encuentra esta situación un proceso indeseable y se siente abandonada por las autoridades.

La responsabilización de un amplio abanico de instituciones, penales, administrativas y asistenciales sigue siendo la orientación dominante por lo que hace a la seguridad ciudadana en Holanda, pero los planteamientos actuales están yendo en una dirección bastante diferente. Las ideas sobre policía de barrio han sido de hecho reemplazadas por nociones sobre la policía como "guardianes" que mantienen alejados a los "elementos indeseables"; "la justicia de proximidad" (Justitie in de Buurt) se redefine como un medio para retrasar la presentación de casos al fiscal; los proyectos de mediación en los barrios y entre vecinos, se dice que son importantes, pero se financian rara vez, y los proyectos de "colectividades comprometidas" (Communities that Care), que fueron importados de los EEUU al final de los 90, se han implementado sólo en cuatro localidades porque se consideran demasiado caros, mientras que el resultado de tan elevadas inversiones no puede ser medido ${ }^{3}$. Los proyectos de mediación en barrios y otras iniciativas con respecto a la justicia restauradora pueden estar proliferando, pero no están financiados de manera estructural y en gran medida dependen de organizaciones de voluntarios. En general, la participación de legos en la justicia es notablemente baja en Holanda.

No resulta exagerado decir que la nueva metáfora para la seguridad ciudadana es "barriendo las calles"- como si se estuviese hablando de suciedad (van Swaaningen, 2005). Tal vez muchos estén de acuerdo con la idea de que las mejoras reales en la seguridad sólo podrán provenir de las mejoras en la vivienda, la cohesión social, la educación, la participación real de las minorías étnicas etc., pero... tales soluciones en colectividad, sociales y culturales son vistas como algo a largo plazo, mientras que ahora lo que se necesita es solucionar problemas para hoy mismo. La gente parece haber perdido la fe en una sociedad "maleable mediante la intervención política" y con tristeza concluye que la represión es la única solución que queda disponible.

\footnotetext{
${ }^{3}$ Con respecto a la justicia de proximidad ( $\left.\mathrm{JiB}\right)$ cabe señalar que algunas oficinas han cerrado (i.e. Haarlem) y otras han manifestado expresamente que no se invierta más en contactos con los barrios y confieren prioridad al rápido crecimiento de casos. El presupuesto reservado para las Communities that Care es de 2,3 millones de euros para toda la provincia de Zuid-Holland (con grandes ciudades como Rótterdam, La Haya, Dordrecht o Leiden), mientras que el presupuesto de seguridad para la sola ciudad de Rótterdam es de 100 millones de euros - excluido el coste "normal" de las intervenciones de la justicia penal. Muchos de los proyectos de prevención del delito son iniciados por instituciones vinculadas al Ministerio de Justicia y el de Asuntos Interiores, y las Communities that Care se organizan principalmente a través del Instituto de Investigación del Ministerio de Asuntos Sociales y Salud Pública (Nederlands Instituut voor Zorg en Welzijn) NIZW.
}

Revista Española de Investigación Criminológica

Artículo 2, Número 5 (2007) $\quad$ www.criminología.net

ISSN: $1696-9219$ 
Si bien los resultados del Informe Cultura y Sociedad 2004 pueden ser críticos con la actual ruptura del estado social de carácter neoliberal, se encuentran en perfecta consonancia con los planes del gobierno para una sociedad más segura. Este dilema y esta paradoja son las presiones más acuciantes en el ámbito local. Las opiniones sobre el delito y el castigo son -más allá de lo que se escucha y ve en los medios de comunicación- informadas prioritariamente por los problemas que se experimentan en las calles. No obstante, también el deseo a favor de más cohesión y más control social encuentran encaje en ese mismo ámbito. Esto significa que los criminólogos tienen buenas razones para prestar atención al ámbito local.

\section{La dimensión local de la seguridad.}

En su libro Crime Control and Community Gordon Hughes y Adam Edwards (2002) sostienen que la dimensión local ofrece un campo más fructífero para la investigación comparada sobre la seguridad ciudadana que el que ofrecen otras esferas de gestión. Esto también es válido para el caso holandés, siendo que en Holanda las líneas maestras de las políticas de seguridad se establecen en los planes de política nacionales. Los problemas de seguridad emergen en el ámbito del barrio o del distrito, pero lo que puede hacerse en ese terreno tiene que encajar con los planes de seguridad de las autoridades locales. A su vez, lo que la ciudad planifica tiene que encajar en los planes nacionales y las decisiones sobre qué iniciativas se financian y cuales no ${ }^{4}$. Las políticas del Estado están cada vez más determinadas por las regulaciones europeas, y éstas en última instancia son dirigidas por planteamientos globales. En todos estos niveles existen decisiones que pueden tomarse de manera más bien autónoma, y condiciones que quedan fijadas en un nivel superior. Para ofrecer un ejemplo concreto de las implicaciones de este planteamiento: se está poniendo en cuestión cada vez con más fuerza hasta qué punto Holanda puede mantener su enfoque "desviado" sobre el consumo de drogas -para el que por otro lado existe bastante apoyo en el nivel nacional.

Con respecto a la seguridad y a la vida cohesionada en comunidad encontramos, sin embargo, algo extraño en juego. Existen dos desarrollos paralelos que parecen apuntar en direcciones muy diferentes. Por un lado, se contempla una clara globalización de la ideología del "modelo de libre mercado", pero por otro, podemos

\footnotetext{
${ }^{4}$ Los municipios reciben en torno al $80 \%$ de sus ingresos del gobierno nacional. Durante los últimos 10 años ha sido una tendencia esperar más de las autoridades locales, pero han recibido menos medios.
}

Revista Española de Investigación Criminológica

Artículo 2, Número 5 (2007) $\quad$ www.criminología.net

ISSN: $1696-9219$ 
observar un retorno a lo nacional y a lo local. El actual gobierno conservador holandés tiene una orientación neoliberal en economía y estado social, pero está inspirado por el comunitarismo en sus propósitos de movilización de la comunidad y en el renovado enfoque sobre normas y valores nacionales.

Con algunos límites, las autoridades locales en Holanda tienen bastante libertad para desarrollar sus propios planes en respuesta a problemas específicos en sus municipios o distritos. Jurídicamente, las cuestiones de orden público -que forman una parte importante de los problemas de seguridad tal como hoy se definen- se deciden en el ámbito local, en lo que se denomina consulta triangular (driehoeksoverleg), entre el alcalde de la ciudad principal en una región policial, el jefe de policía y el fiscal jefe ${ }^{5}$. Si tenemos que analizar la administración y gestión pública local sobre seguridad en Holanda, existen buenas razones para decantarse por Rótterdam.

Rótterdam es la segunda mayor ciudad holandesa, y siempre ha jugado un papel pionero en el desarrollo de nuevos experimentos en materia del control del delito. En ocasiones tales experimentos fueron catalogados de "progresistas" -como en el caso del primer Halt-Project ${ }^{6}$ para delincuentes juveniles en 1981, y en ocasiones de "reaccionarios", como en el caso de los registros preventivos (preventief fouilleren) en ciertos distritos conflictivos, o los intentos de evitar que los "nuevos pobres" se instalasen en esos distritos. Junto a esto, y con sus políticas extremadamente intervencionistas en las familias "problemáticas", Rótterdam ha explorado continuamente "los límites del derecho". Rótterdam es también la única ciudad holandesa que ha experimentado con las Ordenanzas de Comportamiento Antisocial los llamados proyectos 'Haz Normal' (Klok, 2006). Pero también ha sido un campo experimental para planes y políticas urbanas innovadoras. El último ejemplo lo constituye la venta de casas en barrios conflictivos a precios muy bajos, con la condición de que los residentes se ocupen de la renovación de la casa. Este es un posible medio para atraer a nuevos "tipos" de residentes (p. e., con más dinero y mejor nivel educativo) a los barrios conflictivos y conseguir una composición social más

\footnotetext{
${ }^{5}$ Dicho poder político ha sido otorgado por Ley: art 14 de la Ley de Policía (Politiewet) y arts. 219-221 de la Ley de Municipios (Gemeentewet).

${ }^{6}$ Las siglas HALT hacen referencia a la expresión holandesa Het Alternatief, en el marco de las sanciones alternativas. En ciertas infracciones (actos de vandalismo o algunos daños a la propiedad) realizadas por menores la policía puede llevar el caso a la Oficina de HALT, en la que se prepara un proyecto de trabajo, alternativo a la sanción prevista para el caso, no superior a 20 horas de dedicación. La participación en el proyecto es voluntaria, se formaliza por escrito y necesita que haya habido confesión de lo ocurrido y que no se haya participado ya en otros dos Halt-project. ( $N$. de la tr.)
}

Revista Española de Investigación Criminológica

Artículo 2, Número 5 (2007) $\quad$ www.criminología.net

ISSN: $1696-9219$ 
diversificada en tales distritos. Aunque ha despertado bastante interés en compradores potenciales, es demasiado pronto para manifestarse con claridad sobre el éxito del proyecto.

\section{El caso concreto de Rótterdam}

En Rótterdam, la derecha populista fue, desde las elecciones locales de 2002, el principal partido en el Ayuntamiento y ese partido del último Pim Fortuyn dejó huella en las políticas de seguridad de la ciudad (van Swaaningen, 2005). Aunque después de las elecciones locales de 2006 Rótterdam tuvo de nuevo un gobierno laborista, la derecha populista ha mantenido la popularidad y posee el 30 por ciento de los votos y, hasta ahora, los laboristas no han cambiado la política de seguridad urbana. Todo ello guarda una estrecha relación con la historia específica de la ciudad y con la composición de su población. Amplias zonas de la ciudad (especialmente el centro y el nuevo oeste) fueron bombardeadas por los Nazis en 1940 y (por error) también por las fuerzas aliadas en 1942. Esto ha hecho que la ciudad sea muy distinta a otras ciudades holandesas: bloques de casas de escasa calidad construidos muy rápidamente entre 1940 y 1950, y en los últimos diez o quince años muchos rascacielos prestigiosos y autopistas atravesando la ciudad, sin ningún verdadero "centro". Tiene más aire de ciudad grande que, digamos Ámsterdam o Utrecht; y no es un sitio en el que se vea a muchas personas paseando, con las consecuencias que ello implica para el control social.

En segundo lugar, Rótterdam tiene el mayor puerto de Europa y una ubicación excelente para el transporte (por los ríos Rin y Mosa) hacia Alemania y Francia. Esto siempre ha atraído mucha mano de obra a la ciudad; primero desde las provincias del sur del país, luego desde los países mediterráneos y más tarde llegaron (muchos de ellos ilegales) los inmigrantes de los países más pobres (Bouman \& Bouman, 1952; Fijnaut, Moerland \& Uit Beijerse, 1991; Burgers \& Engbersen, 1998). Todos los distritos del sur del río fueron construidos originalmente por los trabajadores del puerto. Hoy en día, la importancia de este inmenso puerto en relación con los problemas de seguridad radica predominantemente en el hecho de que la ciudad es también un centro de distribución de muchas 'mercancías' ilegales, especialmente drogas, pero también inmigrantes de países pobres y sin documentación. Estos dos fenómenos ofrecen un terreno abonado para la especulación inmobiliaria y los delitos callejeros (relacionados con las drogas) (van der Torre, 2004). Resulta llamativo que hoy en día los problemas se encuentren

Revista Española de Investigación Criminológica 
concentrados en los barrios antes mencionados con su historia particular: el centro, el nuevo oeste y el sur.

La imagen estereotipada de Rótterdam es la de una ciudad industrial, predominantemente de clase trabajadora, en la que las camisetas se venden con las mangas ya remangadas. Los holandeses, siguiendo este mismo cliché, tendrían tres capitales: una en la que se gana el dinero (Rótterdam), una en la que se distribuye (La Haya) y otra en la que se gasta (Ámsterdam). Aunque Rótterdam ya no es, en la era post-fordista, el motor de la economía holandesa, sigue siendo cierto que el nivel de formación de su población está por debajo de la media nacional y que, comparativamente, la ciudad atrae a más miembros de la "clase social desfavorecida" de cualquier lugar del mundo que cualquier otra. Merecería la pena que la criminología comparada cotejase Rótterdam con otras grandes ciudades portuarias de Europa, como Amberes, Bilbao, Hamburgo, Liverpool o Marsella, en las que también prácticamente ha desaparecido la industria marítima y se han perdido muchos puestos de trabajo, necesitando generar otros tipos de empleo. Ahora Rótterdam intenta atraer a una población más rica y educada. Pero a pesar de que la ciudad se ha hecho más atractiva de lo que era, pongamos hace quince años, todavía ve marcharse a los segmentos más adinerados de su población. Éste es un hecho especialmente importante si tenemos que comprender la política de seguridad de la ciudad.

Rótterdam siempre ha sido una fortaleza del partido laborista $(P v d A)$. A partir de 1990, el partido laborista empezó a ser firme y continuamente criticado por haber perdido todo contacto con la población. Se decía que el gobierno laborista local actuaba como un regente arrogante incapaz de escuchar y que restaba importancia a las preocupaciones de la gente sobre los delitos callejeros, las tensiones étnicas y el empobrecimiento. Para decirlo en pocas palabras: la gente estaba cansada de los laboristas y quería darles una lección. Catorce años antes, se podía predecir el crecimiento de un partido populista de derechas. Al mismo tiempo el Bloque de la extrema derecha (Vlaams Blok) tuvo su mayor éxito en Amberes, en 1991, el electorado de Rótterdam de extrema derecha era el más alto de Holanda. Estaba tan sólo esperando la legada de un líder carismático. Cuando nuestro departamento presentó su investigación mostrando el deterioro de un concreto barrio del sur de Rótterdam del distrito de Feyenoord a finales de lo 80, todos los ingredientes con los que Fortuyn construyó su programa político sobre seguridad se encontraban ya allí (Fijnaut, 
Moerland \& Uit Beijerse, 1991). Entonces ya habíamos descrito la situación de mezcla entre tensiones étnicas, incivismo y miedo al delito como explosiva (Uit Beijerse \& van Swaaningen, 1993: 293).

La mejora de la seguridad pública fue la tarea más importante que ese nuevo partido se impuso a sí mismo. En consecuencia, la cuestión de la seguridad empezó a jugar un papel cada vez más dominante en la política de Rótterdam que en cualquier otra ciudad holandesa. En 2002, el alcalde (Ivo Opstelten del partido liberal conservador VVD) incluso presentó el hacer de Rótterdam una ciudad más segura como su actividad primaria. Se introdujo una concejalía especial para cuestiones de seguridad (del partido de Fortuyn), se estableció una gran oficina de planificación para cuestiones de seguridad que confeccionó los "índices de seguridad" de ámbito local y de barrio más elaborados de todo el país, así como los llamados "marines urbanos", que son funcionarios de alto nivel con la función de fiscalizar a distintas instituciones a la hora de llevar a cabo sus tareas en la mejora de la situación de seguridad local. Tampoco existe ninguna otra ciudad holandesa en la que el nuevo "urbanismo revanchista" -que hasta ahora sólo conocíamos por las ciudades estadounidenses- sea tan claramente visible como en Rótterdam. Ninguna otra ciudad del país ha puesta tanta energía en la lucha contra la inseguridad de la población -y con ello, en la lucha contra los pobres de la ciudad.

\section{La seguridad en una Rótterdam habitable.}

En un folleto distribuido entre la población de Rótterdam las autoridades locales sostenían en 2001:

La seguridad es nuestra más alta prioridad y una tarea común de todos. No lo es sólo de quienes aplican la ley y de la policía. Éstos son -y seguirán siendo- importantes eslabones en lo que llamamos "la cadena de seguridad", pero existen muchos otros. Tales son los distintos servicios municipales, la compañía de transporte municipal RET, los departamentos municipales de planificación urbanística y vivienda y los de asistencia y servicios sociales, los servicios sanitarios públicos ROTEB, la oficina municipal para la educación, las empresas privadas y las organizaciones sociales. La seguridad debe ser también su más alta prioridad. Todas las actividades de los servicios municipales, de las organizaciones e instituciones que influyen en la seguridad y en la habitabilidad se deben reforzar mutuamente. Las acciones concertadas y armónicas son necesarias, bajo una coordinación estricta. Los consejos de distrito son los primeros responsables de dicha tarea de coordinación. Su enfoque resulta crucial ya que son los más cercanos al ciudadano. Los consejos de distrito, junto con los ciudadanos y todos aquellos que jueguen un papel con respecto a la seguridad, trabajarán para conseguir barrios más seguros y así una Rótterdam más segura 7 .

\footnotetext{
${ }^{7}$ Texto del folleto "cinco años de grograma de acción segura" de Rótterdam (Vijfjarenactieprogramma Veilig), titulado Werken aan een veiliger Rotterdam; geen woorden maar daden, de diciembre de 2001.
}

Revista Española de Investigación Criminológica

Artículo 2, Número 5 (2007) $\quad$ www.criminología.net

ISSN: $1696-9219$ 
Esta cita recuerda la tesis de David Garland (2001) sobre estrategias de responsabilización y el análisis de Adam Crawford (1997) sobre la administración y gestión local del delito. Pero en Rótterdam el papel de la empresa privada y de las iniciativas ciudadanas es menor que en el Reino Unido, y mayor el papel de los servicios municipales (van Swaaningen, 2004). Otro elemento destacado de la política de seguridad en Rótterdam es su tono orientado hacia la acción y los resultados. El término "plan" es cuidadosamente evitado. Según "Una Rótterdam habitable" el pasado se había caracterizado por demasiados planes y muy poca acción.

En un debate sobre la política de seguridad de Rótterdam en septiembre de 2004 celebrado en la Universidad Erasmus, el alcalde Ivo Opstelten confirmó una vez más que si se ganan las elecciones se adquieren responsabilidades. Sostuvo asimismo que la drástica política de seguridad de la ciudad había nacido a partir de un sentido de urgencia, y que ciertamente asumiría las consecuencias políticas si los objetivos de una Rótterdam más segura no se alcanzaban tras 2006, cuando "el programa de acción sobre seguridad" de cinco años se habría implementado por completo. No puede decirse con claridad si esto es meramente retórica inflamada o si el programa de seguridad de Rótterdam de hecho "funciona". Las autoridades locales publican anualmente un "Índice de seguridad" que muestra que las cosas están yendo algo mejor. Dicho índice de seguridad -sobre el que diremos algo más en le próximo epígrafe- integra, sin embargo, muchas estadísticas subjetivas que pueden ser manipuladas con facilidad y que difícilmente podemos calificar de información objetiva. En una interesante evaluación, más bien crítica, la Oficina de Auditorias de Rótterdam concluye que los efectos de la nueva política, sobre la presente situación de seguridad y sobre los sentimientos de inseguridad pueden difícilmente ser medidos, puesto que los datos "objetivos" y las opiniones "subjetivas" se fusionan como una característica propia del índice de seguridad local ${ }^{8}$.

Existe también mucha continuidad en la política de seguridad de Rótterdam. Desde el inicio de los ochenta, la política de prevención del delito holandesa se ha caracterizado por ser una fusión de prevención situacional y social, con aumento de diferentes formas de vigilancia, la aplicación de un llamado enfoque multi institucional

\footnotetext{
${ }^{8}$ En línea en:

http://www.rekenkamer.rotterdam.nl/?/Rekenkamer_Home/Onderzoek/Rapporten?mode=view\&itemID= $\underline{37}$
}

Revista Española de Investigación Criminológica

Artículo 2, Número 5 (2007) $\quad$ www.criminología.net

ISSN: $1696-9219$ 
"integral" sobre la inseguridad y por otorgar un marcado peso a los problemas específicamente urbanos (van Swaaningen, 2002). Todos estos elementos resultan reconocibles en la actual política de seguridad. Tal vez el tono sea lo que más ha cambiado con respecto al pasado. Las principales críticas a las anteriores políticas de seguridad no tenían mucho que ver con su contenido, sino con la forma en la que éstos (no) eran implementados. Había demasiada burocracia, y demasiadas reuniones y planes, pero poca acción, y nunca quedaba claro cuáles eran en la práctica los resultados de algunas intervenciones. Por todo ello, el nuevo programa de acción habla de "prioridades y elecciones claras", de "resultados concretos y visibles" y de "producto final mesurable" (Gemeente Rotterdam, 2002a: 5). No se da una auténtica ruptura con las iniciativas anteriores sobre seguridad y no puede mantenerse tampoco que la ciudad haya acabado con la prevención social del delito. Sería mejor hablar de nuevas estrategias complementarias.

Una de tales estrategias es la orientación claramente actuarial en el trazado de perfiles del delito geográfico: patrones de delincuencia y "zonas calientes" se señalan sistemáticamente. Una segunda estrategia complementaria puede ser caracterizada como "la civilización de los pobres urbanos" (Uitermark \& Duyvendak, 2004). Esta última estrategia se ha convertido en la más visible en la lucha contra el llamado "incivismo", el fuerte acento sobre la necesidad de que las minorías étnicas alcancen una completa "integración" en la sociedad holandesa (aprendiendo el idioma, respetando las costumbres, etc.) y llevando a los "adictos que rehúsan la asistencia" y a las prostitutas que ejercen en la calle hacia un estilo de vida "más respetable". Justus Uitermark y Jan Willem Duyvendak (2004) caracterizan la política social y represiva subyacente diciendo que son "intervenciones con la táctica del palo y la zanahoria con dos elementos característicos: aplauden y promueven la construcción de comunidades vecinales mientras al mismo tiempo contemplan las diferencias culturales como la causa matriz de los problemas urbanos"

Justus Uitermark (2006) concluye que Amsterdam "vende" su política de seguridad como si fuera más social de lo que de hecho es, mientras que Rótterdam la publicita como "más severa" de lo que de hecho es, si bien el resultado de ambas no es diferente en lo fundamental. En un informe del WRR (Consejo Científico para la Política del Gobierno) los sociólogos Godfried Engbersen, Erik Snel y Afke Weltevrede (2005) sostienen que, a pesar de las diferencias existentes entre Ámsterdam y Rótterdam

Revista Española de Investigación Criminológica

Artículo 2, Número 5 (2007) $\quad$ www.criminología.net

ISSN: $1696-9219$ 
-de carácter socio-económico y político- la política de seguridad de ambas ciudades puede caracterizarse como una política de "reconquista social". Es bastante probable que el tono excesivamente "severo" de Rótterdam responda a las demandas del electorado del partido Una Rótterdam Habitable, mientras se sea lo bastante realista para ver que son necesarias provisiones sociales para hacer que funcione dicha política. Aunque los políticos sostienen que el enfoque del "ser severos" se incorpora porque los “ciudadanos de Rótterdam están hartos de medidas blandas", la agenda tradicional laborista en estas cuestiones, si bien en silencio, también se está llevando a cabo.

Las palabras clave del programa de acciones de Rótterdam 2001 son: 1) incivismo (principalmente causado por adictos a las drogas, grupos de jóvenes, prostitutas que ejercen en las calles y mendigos), 2) suciedad y deterioro (el eslogan "barriendo las calles" en sentido literal) y 3) tolerancia cero (barriendo las calles en un sentido metafórico). Con respecto al primer eje de dicha política, los enfoques penal y social ya no se diferencian; la única cuestión relevante es buscar qué funciona para mejorar la situación con respecto a la seguridad. Los "grupos problemáticos" que se conducen de manera incívica con frecuencia son encerrados y colocados bajo la supervisión de los servicios sociales. El segundo eje de la política está inspirado en la filosofía de las "ventanas rotas”. El zumbido político implícito en la acción policial de la tolerancia cero va bastante más allá en el caso de Rótterdam: los sin techo han sido multados por causar lo que se conoce como "molestias visuales (sic!)", sólo por estar durmiendo en un banco o buscar refugio de la lluvia en la marquesina de una parada de tranvía. Se debe señalar, no obstante, que la tolerancia cero también se dirige a los especuladores que facilitan la venta de drogas, explotan a los inmigrantes sin documentación, y que han funcionado como auténticos "matones": i. e. echando a los ciudadanos que cumplen la ley, alquilando casas a numerosos inquilinos muy problemáticos (principalmente a drogodependientes y extranjeros sin documentación), o permitiendo la instalación de burdeles ilegales o centros de producción de drogas, y luego comprando las casas por un precio muy bajo. Aunque legalmente sea difícil, Rótterdam intenta expropiar a los propietarios si se prueba que sabían lo que estaba ocurriendo en sus casas. 


\section{Cinco años de programa de acción y sus prioridades para Rótterdam.}

El programa de acción sobre seguridad de Rótterdam de 2001 contiene no menos de dieciocho prioridades; todas ellas son objetivos que deben realizarse en cinco años. El más importante de ellos es que el llamado "índice se seguridad” en los ocho barrios más problemáticos mejore. Dicho índice está basado en 1) lo que se conoce como "factores objetivos" a partir de estadísticas policiales sobre delitos perpetrados, 2 lo que se conoce como "factores subjetivos" a partir de estadísticas de victimización, también elaboradas por la policía, y 3) lo que se conoce como "estadísticas contextuales" sobre composición étnica, dependencia del sistema asistencial, valor de las viviendas, frecuencia en las mudanzas, etc. Sobre estas bases cada distrito recibe una puntuación: la media actual es un aprobado justito. Aunque es, sin duda, el más elaborado y sistemático sistema de medición de la seguridad en el ámbito de distrito del país, existen muy pocas críticas sobre los efectos colaterales indeseables del índice de seguridad (i.e. estigmatización de ciertos grupos o vecindarios), la fiabilidad de los datos, la inversión extra necesaria para mejorar los niveles de seguridad, o el hecho de que el delito en las calles no sea la única fuente de preocupación. ${ }^{9}$

Una segunda prioridad es abordar los principales "zonas calientes" de delincuencia. La ubicación de estas zonas calientes es realizada con una exactitud tal que se puede referir a un bloque de pisos en el cruce de tal y tal calle. Numerosos emplazamientos son llamados "zonas calientes" porque hay muchos inquilinos por vivienda, se sospecha de la producción o venta ilegal de droga o de la existencia de burdeles ilegales. Las soluciones para estos problemas varían, yendo desde el cierre y derribo de las casas, o su renovación y encarecimiento, hasta la asistencia a los residentes para encontrar empleo o alojamiento. Lo que les ocurrirá a quienes causen molestias en estas zonas calientes, en gran medida, no queda claro. Sin embargo, para los setecientos "gamberros" antisociales (hufters) la cosa está clara: van a ser sacados de las calles y, en la medida de lo posible, encerrados en nuevas instituciones para delincuentes habituales -con unas instalaciones especiales para los adictos a las drogas. Los extranjeros sin documentación válida que hayan cometido un delito serán expulsados, aunque en la práctica esto no sea tan sencillo, sobre todo porque el país de origen es desconocido, o el país en cuestión no los quiere de vuelta. Las personas

\footnotetext{
${ }^{9}$ En este sentido la política de Ámsterdam es diferente: no se otorgan puntuaciones, y la lucha contra el crimen organizado juega un papel mucho mayor.
}

Revista Española de Investigación Criminológica 
adictas a las drogas y las prostitutas (muchas veces también adictas) que consigan "demostrar" que pueden mejorar su estilo de vida recibirán ayuda económica y una vivienda. Para con todos ellos se ha iniciado una ofensiva con la que civilizarlos.

Una tercera prioridad es la Estación Central de Rótterdam. Los resultados de la intensa acción policial en esta estación de trenes se presentan con frecuencia como el mayor éxito en la historia de la ciudad. Durante muchos años había sido el lugar de encuentro de los toxicómanos. La estación tuvo el estatuto especial de "zona de guerra", en la que la policía tenía competencias especiales para controlar las diferentes líneas de transporte público (trenes, metros, tranvías y autobuses) y dispersar cualquier reunión integrada por miembros de las llamadas "categorías de riesgo". Ahora hay menos yonquis en la estación de trenes que antes. Pero después de que se cerrase (en 1994) la "zona libre" (en la que eran tolerados los pinchazos) del "Anden cero" cercano a la estación, los yonquis se trasladaron primero a áreas más vulnerables en el nuevo Oeste de la ciudad (Spangen), donde también se concentraba la prostitución de calle, y luego, al sur (Millinxbuurt) (van der Torre, 2004).

Un resumen de las otras quince prioridades establecidas en el programa de acción, poco añadiría a esta imagen general, ya que todas apuntan en la misma dirección ${ }^{10}$. Incluyen el cierre de las áreas en las que las autoridades habían estado consintiendo la prostitución ilegal en la calle (en Keileweg). Muchas de las mujeres sin documentación trabajando allí tienen que ser expulsadas a sus países de origen, otras son ayudadas a conseguir de nuevo vivir una vida "normal" (libre de drogas), y la mayoría traslada su actividad hacia otros lugares, como Utrecht, que de momento conserva una política más liberal. El resto es tratado como los demás yonquis y "gamberros": i.e. viven en la calle y son encerrados de vez en cuando. Bastante interesante resulta el hecho de que las autoridades presenten la colocación de más

\footnotetext{
${ }^{10}$ Estas son: 4) mejora de la seguridad en el transporte público, 5) cierre de los centros de prostitución (ilegal pero consentida), 6) sacar de las calles a 700 adictos que rehúsan la asistencia 8) sacar de las calles a los delincuentes extranjeros sin documentación válida, 9) más vigilancia, 10) más CCTV, 11) el establecimiento de un servicio al que el ciudadano pueda acudir para presentar sus quejas sobre cuestiones de seguridad 12) cerrar los coffee-shops de drogas blandas que infrinjan la prohibición de causar molestias 13) cerrar los burdeles que infrinjan la prohibición de causar molestias, 14) desmantelar los apartamentos de losq ue se sabe que son lugares de encuentro para los toxicómanos, 15) controlar de manera estricta de las regulaciones sobre seguridad (industriales, entre otras), 16) examen estructural de la integridad personal cuando se entregue a las personas subsidios de desempleo o finiquitos, 17) seguimiento estricto de los protocolos en caso de gestiones de crisis, y, 18) calles más limpias e instalaciones funcionando correctamente (alumbrado de calles, cabinas telefónicas, etc.)
} 
cámaras de CCTV como un objetivo en sí mismo, en lugar de ser un medio para la obtención de otros logros.

Junto a las medidas represivas arriba mencionadas también se propone la planificación urbana como un medio para mejorar la situación sobre seguridad en Rótterdam. Contrariamente a la práctica estadounidense de separación y segregación de las clases sociales más bajas, Rótterdam pretende, como ya hemos visto, establecer una política que mezcle a los miembros de dichas clases con el resto de la población. Una ofensiva para civilizar a los "pobres que no merecen serlo", tolerancia cero para los especuladores (cuyas casas expropiadas se distribuyen), y una política de mezcla de clases sociales caminan de la mano con medidas mucho más controvertidas en la política de seguridad de Rótterdam: impedir a los nuevos inmigrantes que se trasladen a la ciudad. Este planteamiento desencadenó muchas protestas, pero cuando el término "inmigrante" fue reemplazado por la expresión "familias desfavorecidas", la política en cuestión logró establecerse de todos modos. Rótterdam recibió autorización del gobierno nacional para impedir que se registrase como residente en la ciudad cualquiera con ingresos inferiores al $120 \%$ del salario mínimo interprofesional. Uitermark y Duyvendak (2004) dicen al respecto: "Probablemente los efectos de esta propuesta sean limitados (...) pero no obstante resulta significativo que el gobierno central apruebe una medida que contraviene algunos derechos fundamentales (...) Mientras todas estas medidas tienen un aire xenófobo o reaccionario, no puede decirse que pretendan principalmente convertir a la ciudad en una zona de clases medias o altas (...). Las razones para promover la mezcla social tiene más que ver con la gestión de los grupos marginados que con aumentar las bases impositivas." Esto es fácil de entender, ya que el coste de la presencia de grupos marginados es en gran medida financiado por el Estado, mientras que la gestión de dichos grupos es responsabilidad de las autoridades locales $^{11}$. Por su parte Rótterdam sostiene que tiene más grupos problemáticos de los que le corresponde y reclama la solidaridad de otras ciudades para que se lleven su parte.

Sin embargo, con respecto al papel de la sociedad civil en la forma en que se diseñan las iniciativas de seguridad ciudadana podemos observar una gran influencia de las clases medias. Se las escucha, pero al mismo tiempo se coloca a las clases más

\footnotetext{
${ }^{11}$ La cantidad de dinero que el gobierno central paga a los gobiernos locales depende del número de residents, no de la cantidad de impuestos que estos pagan.
} 
desfavorecidas bajo una vigilancia más o menos permanente. El hecho de que el control de las clases desfavorecidas sea generalizado como control de las minorías étnicas, es una de las razones más probables por las que el partido Rótterdam Habitable no haya ganado las elecciones locales en 2006. En el año 2002 muchas minorías étnicas no votaron. En el 2006 lo hicieron y votaron Laborista.

\section{Colaboración y compromiso como precondiciones para el enfoque muti institucional.}

Uno de los problemas centrales de las políticas de seguridad es que las varias instituciones que se supone que deben trabajar conjuntamente, centran tanto su atención en la búsqueda de objetivos internos propios de su institución, que de hecho la cooperación multi-institucional se convierte en una farsa. El estudio de Peter Goris (2000) sobre los agentes profesionales en la política de seguridad de cuatro ciudades flamencas muestra además que, más allá de esta cuestión de la gestión, el éxito de un enfoque multi institucional está determinado en buena medida por la cuestión política de quién determina la agenda.

En el caso de Ámsterdam mencionado en la introducción, la situación en aquel concreto barrio pudo irse de las manos porque las quejas de los residentes no fueron tomadas en serio, falló la comunicación entre los diferentes grupos profesionales (digamos sólo que colaboraron) y no existió el compromiso por hacer de hecho algo para evitar que siguiesen escalando las disputas en el barrio. Las corporaciones municipales de la vivienda, la policía y las autoridades del distrito eran reticentes a usar las competencias que tenían para parar los pies a los grupos de jóvenes. Los destrozos sobre casas y coches y las intimidaciones sobre las personas de las que se recibió noticia no se consideraron lo suficientemente serias. Otros alegaron que tenían miedo de ser acusados de racistas, ya que todos los jóvenes involucrados eran de origen marroquí. Los policías de patrulla sostuvieron que con frecuencia querían intervenir, pero sus jefes les decían que no lo hiciesen, ya que de lo contrario el fiscal -ante quien responde la policía holandesa- revisaría con atención si los hechos y circunstancias habían sido suficientes para la justificar la acusación jurídica de un hecho punible; o si no determinaría que no era un caso para el sistema de justicia penal; o tal vez decidiría que la acción había sido una intervención injustificada que vulneraba la privacidad de las

Revista Española de Investigación Criminológica

Artículo 2, Número 5 (2007) $\quad$ www.criminología.net

ISSN: 1696-9219 
personas etc. 12. Para evitarse tales "obstrucciones" formales, quejas por el procedimiento, y toneladas de burocracia si intervenían, con frecuencia se decidían por no hacer nada.

A la policía y a las autoridades locales de Rótterdam parece importarles algo menos el "formalismo" jurídico que a sus colegas en Ámsterdam -el alcalde ha defendido explícitamente que continuará explorando los límites del derecho. ¿Significa esto que la policía de Rótterdam es menos exigente o está menos comprometida que sus colegas de la capital? Una pregunta similar puede plantearse respecto del la "indiferencia civil" del resto de agentes en el caso de Ámsterdam: la corporación municipal de la vivienda, las autoridades de distrito, los asistentes sociales y el resto de residentes no afectados. ¿Será esto diferente en Rótterdam? Dado que evitar antes que enfrentar los problemas, con la consiguiente "indiferencia civil", parece ser el producto de la era (o cultura?) del individualismo resulta altamente improbable que se de alguna diferencia relevante. Con todo, las autoridades de Rótterdam han desarrollado una iniciativa que da algo más de peso a la colaboración entre los distintos agentes involucrados en la política de seguridad.

En sexto lugar, los llamados "marines urbanos" se responsabilizan de un problema particular de la zona -esta es otra iniciativa copiada del exalcalde de Nueva York Rudolph Giuliani. La primera asociación que provoca la expresión "marine urbano" probablemente sea la de una figura tipo Rambo, pero de hecho se trata de un funcionario de alto nivel con la misión de coordinar la consecución de las dieciocho prioridades del programa de seguridad de Rótterdam en "su" área. Los marines urbanos echan mano de inmediato del "grupo de dirección de la seguridad" integrado por el alcalde, el fiscal jefe, el jefe de policía y el concejal para la seguridad y el orden público. La oficina de planificación de seguridad de la ciudad provee al marine urbano con datos y le otorga apoyo logístico. La principal tarea del marine urbano es forzar a las diferentes partes para que lleguen a un "contrato de resultados", en el que prometen hacer su parte con respecto a la mejora de la seguridad urbana. El éxito de estos marines dependerá en gran medida de las habilidades comunicativas y la capacidad analítica para determinar cuál es el núcleo del problema, quién es responsable y cómo puede

\footnotetext{
${ }^{12}$ Bernard Tomlow, 'Cohen mag burgers niet laten verjagen; probleem bij aanpak van overlast is dat leiderschap en gezag ontbreekt', en: NRC Handelsblad 26 October 2004. El autor es un abogado defensor especializado en desahucios de residentes "anti-sociales", las más de las veces representando a las corporaciones municipales de la vivienda.
}

Revista Española de Investigación Criminológica

Artículo 2, Número 5 (2007) $\quad$ www.criminología.net

ISSN: $1696-9219$ 
resolverse. Tras el 2006 se espera que todos los "eslabones en la cadena de la seguridad" hayan internalizado sus responsabilidades y que los marines urbanos no sean ya necesarios. Pero por el momento siguen siendo una buena palanca -en estricto sentido metafórico por supuesto.

\section{Algunas conclusiones y sugerencias para futuras investigaciones.}

Lo último que puede decirse de la política de seguridad pública de Rótterdam es que sea interesante. Para los juristas, las exploraciones creativas de las autoridades locales sobre los límites del derecho (respecto al registro preventivo, la custodia policial por actos de incivismo, la denegación a los grupos de renta baja de vivir en la ciudad etc.) constituyen un auténtico Edén para la investigación. Las nuevas políticas sobre planeamiento urbanístico y vivienda, el "gobierno de la clase media", y la ofensiva de civilización sobre los -con frecuencia sin papeles o "ilegales"- miembros de la clase más desfavorecida nos llevan al corazón de la investigación sociológica.

Probablemente la cuestión más interesante para los criminólogos sea hasta qué punto la gestión y administración pública de la seguridad se ha convertido en un tema de nosotros, los ciudadanos que cumplimos la ley, contra ellos, los mendigos, drogodependientes, prostitutas de calle, bandas juveniles y especialmente minorías étnicas (musulmanas), y cuales son los posibles contra efectos de esta tendencia. Cuando autores como Malcolm Feeley y Jonathan Simon (1994) o Mike Davis (1998) predijeron conflictos sociales a la entifida, en parte como consecuencia de enfoque fuertemente situacional de la seguridad pública, los criminólogos holandeses básicamente arguyeron "nosotros no vivimos en la zona sur centro de Los Ángeles y Holanda tampoco se va a convertir en algo así." Hoy, después del 11 de septiembre, la muerte del candidato a primer ministro en 2002 y un segundo crimen político de un director de cine en 2004, la gente ya no está segura de eso (van Swaaningen, 2005).

En una perspectiva más concreta, la política pública de seguridad de Rótterdam no es ni tan revolucionaria ni tan exitosa como las autoridades locales nos quieren hacer creer. En último término, se basa en el modelo que fue establecido en el Libro Blanco nacional de 1985 Delito y Sociedad y en el Informe de Seguridad Integral de 1993 (van Swaaningen, 2002). Un concejal del partido de Fortuyn en Rótterdam, Marco Pastors, reconoce en 2004 que: "El partido laborista dice: estáis implementando la política que nosotros hemos puesto en marcha”. Eso es cierto. Y además han desarrollado una buena 
política, por ejemplo, en el caso de la vivienda: no más viviendas de protección oficial, sólo residencias de alto o medio precio para ser ocupadas por propietarios. Simplemente no comunicaron dicha política. No era cuestión de decir "por supuesto construyamos casas caras", no fuese a resultar que dicha política no se llegase a cumplir ${ }^{13}$.

El lenguaje en el que se actualmente se formulan los proyectos políticos definitivamente ha cambiado. Los matices y las bases científicas son reemplazadas por proclamas sobre "la tolerancia cero", "gamberros", "marines" y demás, así como por la retórica encendida de lo simplista del tipo "nosotros contra ellos". El punto clave para la investigación es en qué medida estos cambios en el plano discursivo son de hecho el reflejo de prácticas sustantivas. El planteamiento central de los análisis de Garland de una "cultura del control" se refleja claramente en el caso holandés, y muy especialmente en Rótterdam (van Swaaningen, 2004).

Hemos visto ejemplos de responsabilización - y de los dilemas y dificultades que acompañan dicha estrategia. Un problema importante es la "cultura del distanciamiento" y la "indiferencia civil" que contradice los intentos de los gobiernos de responsabilizar a la ciudadanía y a los agentes profesionales. Otro problema central es que la actual política de seguridad hace probablemente muy difícil alcanzar a todos los grupos que hoy por hoy se encuentran excluidos de la sociedad hasta el punto de que se sientan comprometidos socialmente. Sin embargo esta es exactamente la tarea que el electorado (inmigrante) dio a las autoridades locales en 2006. Los grupos de interés de las personas más excluidas, los yonquis, los extranjeros sin documentación y las trabajadoras callejeras del sexo son, sin embargo, escuchados con mucha dificultad.

Si la sociedad tiene que tornarse menos competitiva y más solidaria, como parece desear la mayoría de la población holandesa según la Oficina de Planificación Social y Cultural, debemos buscar el diálogo y la democracia participativa. Ello requerirá un replanteamiento de la cultura política actual holandesa. Holanda siempre ha sido una democracia liderada por expertos en la que las influencias legas han jugado un papel limitado. Los representantes del sistema de justicia penal siempre han tratado las influencias legas, -jurados, jueces de paz- con desconfianza y han reivindicado un sistema estrictamente profesional. ¿Cómo movilizar las iniciativas populares sobre seguridad urbana si sabemos que muchos son reacios a involucrarse, "el sistema" no

\footnotetext{
${ }^{13}$ Entrevista aparecida en de Volkskrant, el 17 de enero de 2004. El texto aparece traducido al inglés en Uitermark \& Duyvendak, 2004.
}

Revista Española de Investigación Criminológica

Artículo 2, Número 5 (2007) $\quad$ www.criminología.net

ISSN: $1696-9219$ 
está abierto a las influencias "legas" y la sociedad está fragmentada? Para comenzar a dar respuesta a esta pregunta podemos recurrir a una relectura del ensayo de Granovetter's (1977) sobre "la fuerza de los lazos débiles". Tales lazos débiles, que consisten en contactos superficiales sin compromiso han reemplazado a los "lazos fuertes" de las confesiones religiosas o de las posturas para toda la vida. La cuestión es que aunque esos lazos débiles, puedan suponer una menor cohesión social, no necesariamente proveen un menor control social. Los lazos débiles pueden ser más ligeros y menos exigentes, pero también implican un mayor número de vínculos y conexiones. Los lazos fuertes, por su parte, están orientados al interior del grupo, y los contactos con "los de fuera" son relativamente escasos. Desde esta perspectiva, el tan a menudo criticado individualismo no es necesariamente tan preocupante.

Por ultimo desearía señalar algunos temas interesantes de investigación con respecto a la administración pública y social. La tesis de la "gobernance" es lo primero que viene en mente. La mayoría de la literatura académica sobre este tema critica el nuevo estilo "empresarial" de administrar por sus déficits democráticos, pero actualmente parece más emocionada buscando a ver si no habrá puntos positivos para ser descubiertos. También se escucha a los funcionarios progresistas de Rótterdam decir que prefieren el "todo es posible" al estilo de la derecha populista a la "jaula de hierro" que los laboristas construyeron en el pasado. Sostienen que ahora hay más transparencia y menos papeleo, y que se hacen esfuerzos serios por resolver el problema de la permisividad; y que había pocas estructuras comprometidas en las primeras políticas de seguridad en comparación con la actual cooperación entre instituciones. Esta parece ser una importante lección que las nuevas autoridades laboristas de Rótterdam deberían tener muy presente.

Cuando empecé a trabajar en el ámbito de la seguridad ciudadana, creía que era una de las áreas más aburridas de la criminología: se ocupaba de problemas menores, se basada en planes burocráticos mal informados, con poco contenido y acción. En ningún lugar había visto estudios tan tediosos, repetitivos, poco interesantes desde el punto de vista instrumental o intelectual sobre costes y efectos de la intervención $\mathrm{X}, \mathrm{Y}$ o $\mathrm{Z}$ en el barrio A, B y C. Realmente me llevó algún tiempo descubrir cuan interesante es este ámbito de investigación. Entra en contacto con todas las cuestiones importantes de sociología y las hace muy concretas a un nivel práctico y local. Y eso fue lo que en primera instancia me había llevado a la criminología. Además creo que hay pocas

Revista Española de Investigación Criminológica

Artículo 2, Número 5 (2007) $\quad$ www.criminología.net

ISSN: $1696-9219$ 
ciudades que ofrezcan un campo de investigación más interesante que

Rótterdam...incluso si soy bastante escéptico, cuando no me siento preocupado, sobre hacia adónde nos van a conducir las nuevas políticas.

\section{Referencias}

Beijerse, Jolande uit \& René van Swaaningen (1993): "Social control as a policy: pragmatic moralism with a structural deficit.", en: Social \& Legal Studies vol.2, pp. 281-302 Existe versión castellana bajo el título "El Control Social como Política Estatal: Moralismo Pragmático con Déficit Estructural. La falacia de la prevención del delito en los Países Bajos", en: Roberto Bergalli (ed.), Sistema Penal e Intervenciones Sociales; algunas experiencias nacionales, regionales y locales en Europa. Barcelona: Hacer, pp.177-219

Bouman, P.J. \& W.H. Bouman (1952): De groei van de grote werkstad; een studie over de bevolking van Rotterdam. Assen: Van Gorcum.

Brizée, R. (1985): 'Onrustgevoelens in Nederland; een analyse van 25 jaar TweedeKamerdebatten over criminaliteit in Nederland 1960-1984', en: Tijdschrift voor Criminologie vol.27, pp. 177-188.

Bunt, Henk van de \& René van Swaaningen (2004):, 'Van criminaliteitsbestrijding naar angstmanagement', en: Erwin Muller (ed.) Veiligheid; studies over inhoud, organisatie en maatregelen. Alphen aan den Rijn: Kluwer, pp. 661-673.

Burgers, Jacques \& Godfried Engbersen (eds.) (1998): De ongekende stad 1; illegale vreemdelingen in Rotterdam. Amsterdam: Boom.

Burney, Elizabeth (2005): Making People Behave; anti-social behaviour, politics and policy. Collumpton: Willan.

Crawford, Adam (1997): The Local Governance of Crime; appeals to community and partnerships. Oxford: Clarendon.

Crawford, Adam (ed.) (2002): Crime and Insecurity; the governance of safety in Europe. Cullompton: Willan.

Davis, Mike (1998): Ecology of Fear; Los Angeles and the imagination of disaster. New York: Holt \& Co.

Downes, David \& René van Swaaningen (forthcoming) 'The Road to Dystopia; changes in the penal climate in the Netherlands', in: Michael Tonry \& Catrien Bijleveld (eds.) Crime and Justice in the Netherlands. Chicago: Chicago University Press Crime and Justice Series vol.35.

Engbersen, Godfried, Erik Snel \& Afke Weltevrede (2005): Sociale herovering in Amsterdam en Rotterdam: één verhaal over twee wijken. Amsterdam: Amsterdam University Press/WRR

Feeley, Malcolm \& Jonathan Simon (1994): 'Actuarial Justice; the emerging new criminal law', in: David Nelken (ed.) The Futures of Criminology. London: Sage, pp.173-201.

Fijnaut, Cyrille JCF, Hans Moerland \& Jolande uit Beijerse (1991): Een winkelboulevard in problemen; samenleving en criminaliteit in twee Rotterdamse buurten. Arnhem: Gouda Quint

Garland, David (2001): The culture of control; crime and social order in contemporary society. New York: Oxford University Press.

Gemeente Rotterdam (2002a): Vijfjarenactieprogramma Veiligheid Rotterdam. Rotterdam: Programmabureau Veilig.

Gemeente Rotterdam (2002b): Het nieuwe elan van Rotterdam... en zo gaan we dat doen. Rotterdam: College van B\&W.

Goris, Peter (2000): Op zoek naar de krijtlijnen van een sociaal rechtvaardige veiligheidszorg; analyse van relaties tussen professionele actoren in het kader van een geïntegreerde preventieve aanpak van veiligheidsproblemen in achtergestelde woonbuurten. Tesis doctoral inédita. Universidad Católica de Lovaina.

Revista Española de Investigación Criminológica

Artículo 2, Número 5 (2007) $\quad$ www.criminología.net

ISSN: $1696-9219$ 
Granovetter, Mark S. (1973): 'The strength of weak ties', en: American Jorunal of Sociology vol.78, pp.1360-1380.

Hughes, Gordon \& Adam Edwards (eds.) (2002): Crime Control and Community; the new politics of public safety. Cullompton: Willan.

Klok, Thérèse (2006): ASBO: Fighting Smoke. Rotterdam: Trabajo doctoral sin publicar del Master de Criminología, Rotterdam: Universidad Erasmus.

Swaaningen, René van (2002): 'Towards a replacement discourse on community safety; lessons from the Netherlands', en: Gordon Hughes, Eugene McLaughlin \& John Muncie (red.) Crime Prevention and Community Safety: New Directions. London: Sage, pp. 260-278.

Swaaningen, René van (2004): 'Veiligheid in Nederland in Europa: een sociologische beschouwing aan de hand van David Garland', en: Justitiële Verkenningen vol.30, no.7, pp. 9-23.

Swaaningen, René van (2005): 'Public Safety and the Management of Fear', in: Theoretical Criminology vol. 9, no.3, pp.289-306. Existe versión castellana bajo el título "La política de seguridad ciudadana en Holanda: traficando con el miedo." en Revista Española de Investigación Criminológica, n. 3, 2005, online en:

http://www.criminologia.net/contenidos/revistaContenido/3/ac22005.pdf

Torre, Edward van der (2004): 'Rotterdamse drugsscenes; het kostbare gelijk van de straat, en: Erwin Muller (ed.), Veiligheid; studies over inhoud, organisatie en maatregelen. Alphen aan den Rijn: Kluwer, pp. 253-278.

Uitermark, Justus \& Jan Willem Duyvendak (2004) 'Civilizing the European city; revanchist urbanism in Rotterdam, the Netherlands' (trabajo presentado en el encuentro annual de la asociación Americana de Sociologia, celebrado entre el 14 y el 17 de agosto 204 en San Francisco).

Uitermark, Justus (2006): 'Grootstedelijke cijferpolitiek: Rotterdam na vier jaar niet leefbaarder dan Amsterdam', en: Tijdschrift voor de Sociale Sector, March, pp. 34-39.

Vries, Ido de (2004): 'Communities that Care: an evidence based strategy of preventing juvenile problem behavior; on the role of municipalities in dealing with juvenile criminal behaviour in the Netherlands and how the strategy of Communities that Care offers tools for well administrating a preventive youth policy' (trabajo presentado en el Congreso Annual de la Sociedad Europea de Criminología , celebrado del 25 al 28 de agosto de 2004 en Amsterdam, disponible en línea en: www.esc-eurocrim.org/files/paper ctc.doc ).

Wit, Ria de (2002): 'Stadsmariniers stuwende kracht voor veiliger Rotterdam', en: Nieuw Rotterdams Tij, n.11, pp. 4-7. 